\title{
Clinical Outcomes of Recombinant Human-soluble Thrombomodulin Treatment for Disseminated Intravascular Coagulation in Solid Tumors
}

\author{
SHINICHIRO KASHIWAGI ${ }^{1}$, YUKA ASANO ${ }^{1}$, KATSUYUKI TAKAHASHI ${ }^{2}$, MASATSUNE SHIBUTANI $^{3}$, \\ RYOSUKE AMANO $^{4}$, SHUHEI TOMITA ${ }^{2}$, KOSEI HIRAKAWA ${ }^{1,3}$ and MASAICHI OHIRA ${ }^{1,3}$ \\ ${ }^{1}$ Department of Breast and Endocrine Surgery, Osaka City University Graduate School of Medicine, Osaka, Japan; \\ ${ }^{2}$ Department of Pharmacology, Osaka City University Graduate School of Medicine, Osaka, Japan; \\ ${ }^{3}$ Department of Gastrointestinal Surgery, Osaka City University Graduate School of Medicine, Osaka, Japan; \\ ${ }^{4}$ Department of Hepato-Biliary-Pancreatic Surgery, \\ Osaka City University Graduate School of Medicine, Osaka, Japan
}

\begin{abstract}
Disseminated intravascular coagulation (DIC) that occurs during cancer therapy prevents continuation of therapy, contributing to a worse prognosis. While recombinant humansoluble thrombomodulin (rhTM), a new DIC drug, has occasionally shown its efficacy in DIC associated with infection and blood cancer, its efficacy in patients with solid tumors has been unproven. This review presents the results on the efficacy and safety of rhTM as a DIC drug in patients with solid tumors that have been confirmed by the clinical data of three previous reports. The number of cases in each study was 101, 123 and 40. The respective DIC resolution rate was $34.0 \%, 35.2 \%$ and $32.5 \%$, and the 28-day survival rate was $55.4 \%, 52.0 \%$ and $40.0 \%$. Although comparison with other anti-DIC therapies is required, rhTM therapy is considered one of the treatment options of DIC in patients with solid tumors.
\end{abstract}

Cancer patients are in a chronic hypercoagulable state and are more likely to develop disseminated intravascular coagulation (DIC) from infection and anticancer therapy (such as chemotherapy and surgical treatment) $(1,2)$. DIC

This article is freely accessible online.

Correspondence to: Shinichiro Kashiwagi, MD, Ph.D., Department of Breast and Endocrine Surgery, Osaka City University Graduate School of Medicine, 1-4-3 Asahi-machi, Abeno-ku, Osaka 5458585, Japan. Tel: +81 666453838, Fax: +81 666466450, e-mail: spqv9ke9@view.ocn.ne.jp

Key Words: Recombinant human-soluble thrombomodulin, disseminated intravascular coagulation, solid tumor, tissue factor, review. that occurs during cancer therapy makes it difficult to continue treatment, contributing to poor prognosis $(3,4)$. Therefore, treatment and systemic management aimed at early DIC withdrawal are needed.

On the other hand, while recombinant human-soluble thrombomodulin (rhTM), which is attracting attention as a new DIC therapeutic agent (5), has occasionally shown its efficacy in DIC associated with infection and blood cancer (6), its usefulness in patients with solid tumors has not been proven (7-9). In this paper, we describe the efficacy and safety of rhTM as DIC treatment in solid tumor patients.

\section{Cancer Patients and Disseminated Intravascular Coagulation (DIC)}

DIC is a clinical condition in which fibrin clots form within the blood vessels due to the increased coagulation activity throughout the body, eventually clogging the small blood vessels $(10,11)$. Clinical symptoms include multiorgan failure caused by organ hypoperfusion due to vascular occlusion and bleeding tendency caused by the consumption of platelets and coagulation factors (2).

In 1865, Trousseau reported that there was a high incidence of venous thrombosis in gastric cancer cases (Trousseau's syndrome), and since then, an association between cancer patients and thrombosis/hypercoagulable state has been suggested $(12,13)$. Cancer patients are in a hypercoagulable state (1), which can contribute to thrombophlebitis, venous thrombosis, and also DIC $(3,13)$.

To evaluate the underlying disease of DIC in Japan, a questionnaire survey at University Hospitals has been conducted by the Study Group on Blood Coagulation 
Abnormalities under the Specified Disease Program (14). This survey showed that 2,193 cases of DIC occurred annually at 243 facilities. These included 608 cases (29\%) of solid tumors and 513 cases $(20 \%)$ of hematopoietic neoplasms, suggesting that half of the cases were caused by malignancy. The frequency of patients with solid tumors presenting DIC was 142 (23.4\%) with hepatocellular cancer, which was the highest rate, 99 with lung cancer (16.3\%), 93 with gastric cancer (15.3\%), and 65 (10.7\%) with colon cancer. The incidence of DIC was higher in bile duct cancer $(7.3 \%)$ and pancreatic cancer $(5.7 \%)$.

\section{Pathogenic Mechanism of DIC in Solid Tumors}

Malignancy results in a hypercoagulable state by the production/release or cell surface expression of procoagulant factors by tumor cells, by the release of procoagulant factors into the blood associated with disintegration of tumor cells/tissue cells, and by the expression of procoagulant factors in the lymphocytes/monocytes/macrophage lineage cells stimulated by the host immune response to tumor cells (12) (Figure 1). Tissue factor (TF) is an important procoagulant factor $(15,16)$. TF expressed on the cell membrane, activates coagulation factor VII in the presence of activated coagulation factor X. Many tumor cells in hematopoietic tumors and solid tumors express a large amount of TFs, and TFs released following the disintegration of these tumor cells are considered to cause a general hypercoagulable state (17). It has been demonstrated that TFs are expressed not only in cancer cells, but also in tumorassociated macrophages existing in cancer tissue stroma, where they affect the cancer microenvironment. Furthermore, in a tumor-bearing state, inflammatory cytokines (such as tumor necrosis factor alpha and interleukin) increase the expression of TFs in the monocytes and vascular endothelial cells, contributing to a hypercoagulable state. Additionally, development of infection and sepsis lead to further activation of inflammatory cytokines and worsens DIC.

\section{DIC Treatment in Cancer Patients}

The cornerstone of DIC treatment of cancer patients includes treatment of the underlying disease, anticoagulant therapy, replacement therapy, and systemic control (18-20). Treatment of the underlying disease means chemotherapy, radiation therapy, endocrine therapy, or surgical treatment, depending on the type of cancer. Treatment of the underlying disease is the most important, and success in the treatment of the primary disease contributes to withdrawal from $\operatorname{DIC}(21,22)$. In chemotherapy and radiation therapy, however, TFs released by rapid disintegration of cancer cells have the risk of causing or worsening DIC, and as such, cautious treatment is required. In surgical treatment, inflammation caused by invasion and mechanical stimulation can possibly worsen the hypercoagulative state and induce DIC by stimulating a blood-clotting reaction. As for anticoagulant therapy, there is a report that using chemotherapy for solid tumors in combination with low-molecular-weight heparin reduces the mortality rate $(19,20)$.

In DIC, overproduction of thrombin is caused by the abovementioned mechanisms. As a result, a frequent occurrence of fibrin clots within the microvessels throughout the body causes ischemic organ damage, and decrease in platelets and clotting factors due to the overproduction of thrombin and excessive activation of the fibrinolytic system leads to a tendency to bleed. Thrombomodulin (TM) is a glycoprotein present on vascular endothelial cells and is a physiological anticoagulant factor responsible for regulating vascular coagulation in living organisms (23). Recombinant soluble TM ectodomain that includes the active parts of human TM is produced in animal cells by genetic engineering, and it is used to improve the symptoms of DIC by a novel vascular coagulation regulating mechanism through protein $\mathrm{C}(5)$.

\section{DIC Treatment with Recombinant Human-soluble Thrombomodulin in Patients with Solid Tumors}

While reports on the efficacy and safety of rhTM for infectious DIC are scattered (6), there have been few studies on solid tumor DIC (7-9) (Table I), for example, a prospective cohort study by Tamura K et al. (7). The latter study was conducted on 101 patients who developed DIC associated with a solid tumor, and the duration of administration of rhTM was 6-14 days. The DIC resolution rate after the administration of rhTM was $34.0 \%$ (Table II). A total of $90.9 \%$ of patients who responded to rhTM survived beyond the 28th day of treatment (28-day outcome). On the other hand, 59.4\% of the patients who did not respond to rhTM died by the 28th day. Regarding efficacy, in $34.0 \%$ of patients DIC was resolved, and the 28-day survival rate was $55.4 \%$. With regard to the test values, a significant reduction in fibrin degradation product (FDP), thrombin-antithrombin complex (TAT), plasmin- $\alpha 2$ plasmin inhibitor complex (PIC), and D-dimer was shown after the administration of rhTM. Additionally, a multicenter retrospective observational study of 123 cases has shown that the causes of DIC were cancer in $38.2 \%$ of cases, and infection in $51.2 \%$, and also gastric cancer and colorectal cancer were the most frequent (8). Regarding efficacy, in $35.2 \%$ of patients DIC was resolved, and the 28-day survival rate was $52.0 \%$. In the survival analysis, cancer-related DIC had a significantly poorer prognosis compared to infection-related DIC ( $p=0.016$, logrank test). Furthermore, a significant reduction in DIC score, FDP, and prothrombin time-international normalized ratio (PTINR) was observed. Patients who were relieved of DIC had a 


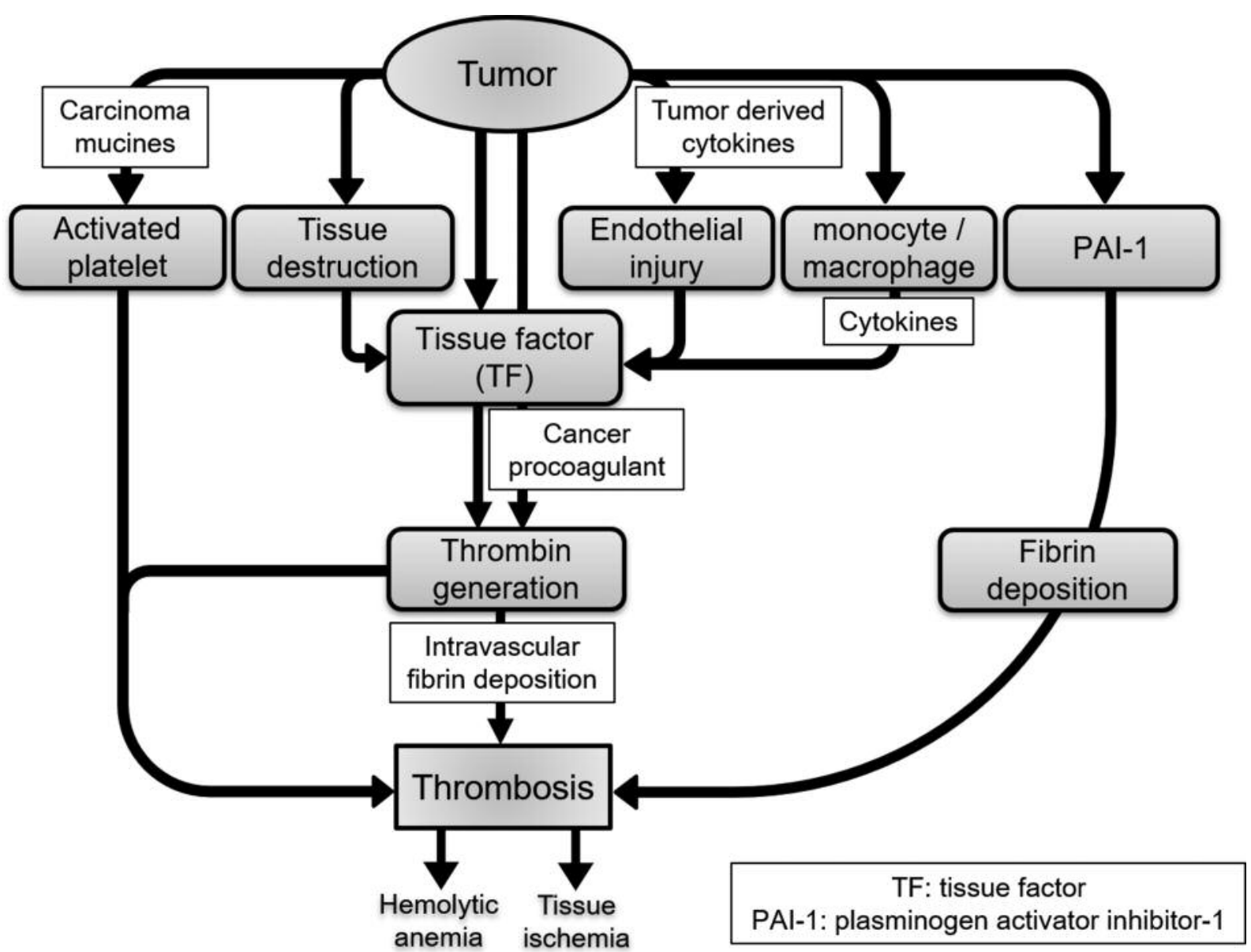

Figure 1. Mechanism of disseminated intravascular coagulation in solid tumors. Malignancy causes a hypercoagulation state by the production/release or cell surface expression of a procoagulant factors by tumor cells, by the release of a procoagulant factors into the blood associated upon disintegration of tumor cells/tissue cells, and by the expression of a procoagulant factors in lymphocytes/monocytes/macrophage lineage cells stimulated by host immune response to tumor cells. Tissue factor (TF) is an important procoagulant factor. TF expressed on the cell membrane activates coagulation factor VII in the presence of activated coagulation factor X.

good prognosis compared to patients who were not relieved of DIC $(p<0.001, \log$-rank test). As for chemotherapy, the patients treated with chemotherapy had a significantly better prognosis compared to patients who were not treated with chemotherapy ( $p=0.001, \log$-rank test). In the multivariate analysis, chemotherapy and alleviation of DIC were independent factors contributing to survival $(p=0.001 ; 95 \%$ confidence interval $[\mathrm{CI}]=0.18-0.64$; hazard ratio $[\mathrm{HR}]=0.34$ ) $(p=0.01,95 \% \mathrm{CI}=0.30-0.88 ; \mathrm{HR}=0.52)$. Based on these facts, it has been argued that "treatment of the primary disease and treatment of DIC are important for survival". Moreover, another study, at the Osaka City University, was conducted on 40 patients with solid cancer out of 208 patients with DIC (9). Cancer cases included 17 patients $(42.5 \%)$ with cancer of the digestive system, 15 patients $(37.5 \%)$ with urinary system cancer and 8 patients $(20.0 \%)$ with other types of cancer. Clinical symptoms included 7 cases of bleeding (17.5\%) and 5 cases of blood clots (12.5\%). A total of 26 cases were associated with infection $(65.0 \%)$. As for the efficacy, $32.5 \%$ of patients were relieved of DIC, and the 28 day survival rate was $40.0 \%$. The number of days required to resolve DIC was $3.0 \pm 1.5$ days, and the number of days of administration of rhTM was 5.0 \pm 2.7 days. Adverse events were observed in 4 patients $(10.0 \%)$; 3 cases of bleeding and 1 case of liver enzyme levels elevation. The study on the resolution of DIC and clinical factors showed that it was very difficult for the patients who experienced bleeding to be relieved of DIC $(p=0.043)$. The patients who were relieved of DIC, had a significantly better outcome compared to patients who were not relieved of DIC $(p<0.001)$. These results showed the efficacy and safety of rhTM for treating DIC associated with solid tumors. 
Table I. Baseline demographics and disease characteristics of the patients.

\begin{tabular}{|c|c|c|c|c|}
\hline Study author/year & Number of patients & Gender & Age (years), median & Types of tumors \\
\hline Asano Y, et al. 2014 (9) & 40 & $\begin{array}{l}\text { M } 27(67.5 \%) \\
\text { F } 13(32.5 \%)\end{array}$ & $\begin{array}{c}68.5 \\
(28-84)\end{array}$ & $\begin{array}{l}\text { Gastrointestinal cancer } 17(42.5 \%) \text {, } \\
\text { urological cancer } 15(37.5 \%), \text { etc. }\end{array}$ \\
\hline Tamura K, et al. 2015 (7) & 101 & $\begin{array}{c}\text { M } 63(62.4 \%) \\
\text { F } 38(37.6 \%)\end{array}$ & $\begin{array}{c}67 \\
(23-86)\end{array}$ & $\begin{array}{c}\text { Lung cancer } 24(23.8 \%) \text {, gastric cancer } \\
21(20.8 \%) \text {, breast cancer } \\
15(14.9 \%) \text {, pancreatic cancer } \\
11(10.9 \%) \text {, colorectal cancer } 9(8.9 \%), \\
\text { biliary tract cancer } 7(6.9 \%), \\
\text { prostate cancer } 3(3.0 \%), \text { etc. }\end{array}$ \\
\hline Ouchi K, et al. 2018 (8) & 123 & $\begin{array}{l}\text { M } 87(70.7 \%) \\
\text { F } 36(29.3 \%)\end{array}$ & $\begin{array}{c}65 \\
(30-84)\end{array}$ & $\begin{array}{c}\text { Gastric cancer } 39(31.7 \%), \text { colorectal } \\
\text { cancer } 25(20.3 \%), \text { pancreatic cancer } \\
12(9.8 \%), \text { Biliary tract cancer } 10(8.1 \%) \\
\text { esophageal cancer } 9(7.3 \%), \\
\text { lung cancer } 4(3.3 \%), \text { etc }\end{array}$ \\
\hline
\end{tabular}

M: Male; F: female.

Table II. Clinical outcomes of efficacy and safety.

\begin{tabular}{lcccc}
\hline & \multicolumn{2}{c}{ Efficacy } & & Safety \\
\cline { 2 - 3 } Study author/year & DIC resolution rate (\%) & Survival rate at 28 days (\%) & Complications (\%) \\
\hline Asano Y, et al. 2014 (9) & 39.7 & 41.3 & 10.0 (bleeding 7.5, liver enzyme elevation 2.5) \\
Tamura K, et al. 2015 (7) & 34.0 & 55.4 & & 12.9 (serious bleeding-related adverse events 5.0, etc.) \\
Ouchi K, et al. 2018 (8) & 35.2 & 52.0 & \\
\hline
\end{tabular}

DIC: Disseminated intravascular coagulation.

Treatment of DIC associated with solid tumors depends on the DIC diagnostic criteria. The Japanese Ministry of Health and Welfare (24), the International Society on Thrombosis and Haemostasis and the Japanese Association for Acute Medicine $(25,26)$ have issued DIC diagnostic criteria and the application of different criteria may result in different results. Therefore, it is necessary to establish universally accepted DIC diagnostic criteria to increase agreement among studies. DIC associated with solid tumors includes many cases that develop as chronic DIC and lowgrade DIC, and it is desirable to establish DIC criteria also for these pathophysiological mechanisms.

Additionally, the mechanism of action of rhTM in DIC has been examined in several studies. It has been demonstrated that rhTM has not only anticoagulant effect but also anti-inflammatory effect (27). This anti-inflammatory effect of rhTM has been confirmed also in a study using sepsis models (28). Furthermore, it has been shown that rhTM and the N-terminal lectin-like domain 1 of rhTM exert their anti-inflammatory effect of rhTM by binding to high mobility group box 1 (HMGB-1) (29). There has also been a report clarifying the mechanism of the anti-inflammatory effect of rhTM through Toll-like receptor (TLR) 4 in hepatic ischemia-reperfusion injury (30). Thus, the antiinflammatory effect of rhTM suggests that rhTM modifies the tumor microenvironment in solid tumors.

\section{Conclusion}

The epidemiology, pathogenic mechanism, and treatment outcome of DIC in patients with solid tumors were reviewed. Although comparison with other anti-DIC therapies is required, rhTM is considered one of the treatment options for DIC in patients with solid tumors.

\section{Conflicts of Interest}

All of the Authors have no conflicts of interest to disclose.

\section{Authors' Contributions}

SK participated in the design of the study and drafted the manuscript. YA, KT, MS and RA helped with study data collection and manuscript preparation. ST, KH and MO conceived the study, and participated in its design and coordination and helped to draft the manuscript. All authors have read and approved the final manuscript. 


\section{Acknowledgements}

The Authors would like to thank Yayoi Matsukiyo and Tomomi Okawa (Department of Breast and Endocrine Surgery, Osaka City University Graduate School of Medicine) for helpful advice regarding data management. Sources of support: This study was funded by grants from the Japan Society for the Promotion of Science (KAKENHI, Nos. 17H07023, 26461957, and 17K10559) to Shinichiro Kashiwagi.

\section{References}

1 Kakkar AK, DeRuvo N, Chinswangwatanakul V, Tebbutt S and Williamson RC: Extrinsic-pathway activation in cancer with high factor viia and tissue factor. Lancet 346(8981): 1004-1005, 1995. PMID: 7475548.

2 Gando S, Levi $\mathrm{M}$ and Toh $\mathrm{CH}$ : Disseminated intravascular coagulation. Nat Rev Dis Primers 2: 16037, 2016. PMID: 27250996. DOI: $10.1038 / \mathrm{nrdp} .2016 .37$

3 Kawasugi K, Wada H, Hatada T, Okamoto K, Uchiyama T, Kushimoto S, Seki Y, Okamura T, Nobori T and Japanese Society of Thrombosis Hemostasis DICS: Prospective evaluation of hemostatic abnormalities in overt dic due to various underlying diseases. Thromb Res 128(2): 186-190, 2011. PMID: 21429565. DOI: 10.1016/j.thromres.2011.02.015

4 Sallah S, Wan JY, Nguyen NP, Hanrahan LR and Sigounas G: Disseminated intravascular coagulation in solid tumors: Clinical and pathologic study. Thromb Haemost 86(3): 828-833, 2001 PMID: 11583315.

5 Maruyama I: Recombinant thrombomodulin and activated protein $\mathrm{c}$ in the treatment of disseminated intravascular coagulation. Thromb Haemost 82(2): 718-721, 1999. PMID: 10605773.

6 Saito H, Maruyama I, Shimazaki S, Yamamoto Y, Aikawa N, Ohno R, Hirayama A, Matsuda T, Asakura H, Nakashima M and Aoki N: Efficacy and safety of recombinant human soluble thrombomodulin (art-123) in disseminated intravascular coagulation: Results of a phase iii, randomized, double-blind clinical trial. J Thromb Haemost 5(1): 31-41, 2007. PMID: 17059423. DOI: $10.1111 / \mathrm{j} .1538-7836.2006 .02267 . x$

7 Tamura K, Saito H, Asakura H, Okamoto K, Tagawa J, Hayakawa $\mathrm{T}$ and Aoki $\mathrm{N}$ : Recombinant human soluble thrombomodulin (thrombomodulin alfa) to treat disseminated intravascular coagulation in solid tumors: Results of a one-arm prospective trial. Int J Clin Oncol 20(4): 821-828, 2015. PMID: 25385713. DOI: $10.1007 / \mathrm{s} 10147-014-0768-1$

8 Ouchi K, Takahashi S, Chikamatsu S, Ito S, Takahashi Y, Kawai S, Okita A, Kasahara Y, Okada Y, Imai H, Komine K, Saijo K, Takahashi M, Shirota H, Takahashi M, Gamoh M and Ishioka C: Retrospective analysis on the clinical outcomes of recombinant human soluble thrombomodulin for disseminated intravascular coagulation syndrome associated with solid tumors. Int J Clin Oncol 23(4): 790-798, 2018. PMID: 29511940. DOI: 10.1007/ s10147-018-1261-Z

9 Asano Y, Kashiwagi S, Shibutani M, Yamazoe S, Noda S, Sakurai K, Nagahara H, Kimura K, Kawajiri H, Toyokawa T, Amano R, Kubo N, Tanaka H, Muguruma K, Ohtani H, Takashima T, Yashiro M, Onoda N, Maeda K, Ohira M and Hirakawa K: Effect of recombinant human soluble thrombomodulin in patients with solid carcinoma with dic. Gan To Kagaku Ryoho 41(12): 2503-2505, 2014. PMID: 25731571.
10 Levi M, de Jonge E, van der Poll $\mathrm{T}$ and ten Cate $\mathrm{H}$ : Disseminated intravascular coagulation. Thromb Haemost 82(2): 695-705, 1999. PMID: 10605770.

11 Levi M and Ten Cate H: Disseminated intravascular coagulation. N Engl J Med 341(8): 586-592, 1999. PMID: 10451465. DOI: 10.1056/NEJM199908193410807

12 Varki A: Trousseau's syndrome: Multiple definitions and multiple mechanisms. Blood 110(6): 1723-1729, 2007. PMID: 17496204. DOI: 10.1182/blood-2006-10-053736

13 Sack GH Jr., Levin J and Bell WR: Trousseau's syndrome and other manifestations of chronic disseminated coagulopathy in patients with neoplasms: Clinical, pathophysiologic, and therapeutic features. Medicine (Baltimore) 56(1): 1-37, 1977. PMID: 834136.

14 Nakagawa $M$ and Tsuji $\mathrm{H}$ : Current trends in the diagnosis of disseminated intravascular coagulation in japan: Findings of questionnaire survey. Rinsho Ketsueki 40(5): 362-364, 1999. PMID: 10390881.

15 Morrissey JH: Tissue factor: An enzyme cofactor and a true receptor. Thromb Haemost 86(1): 66-74, 2001. PMID: 11487043.

16 Kasthuri RS, Taubman MB and Mackman N: Role of tissue factor in cancer. J Clin Oncol 27(29): 4834-4838, 2009. PMID: 19738116. DOI: 10.1200/JCO.2009.22.6324

17 Nakasaki T, Wada H, Watanabe R, Mori Y, Gabazza EC, Kageyama S, Nishikawa M and Shiku H: Elevated tissue factor levels in leukemic cell homogenate. Clin Appl Thromb Hemost 6(1): 14-17, 2000. PMID: 10726043.

18 Labelle CA and Kitchens CS: Disseminated intravascular coagulation: Treat the cause, not the lab values. Cleve Clin J Med 72(5): 377-378, 383-375, 390 passim, 2005. PMID: 6596191.

19 Pernerstorfer T, Hollenstein U, Hansen J, Knechtelsdorfer M, Stohlawetz P, Graninger W, Eichler HG, Speiser W and Jilma B: Heparin blunts endotoxin-induced coagulation activation. Circulation 100(25): 2485-2490, 1999. PMID: 10604885.

20 Levi M: Disseminated intravascular coagulation in cancer patients. Best Pract Res Clin Haematol 22(1): 129-136, 2009. PMID: 19285279. DOI: 10.1016/j.beha.2008.12.005

21 Rhee KD, Yu J, Zhao CY, Fan G and Yang XJ: Dnmt1-dependent DNA methylation is essential for photoreceptor terminal differentiation and retinal neuron survival. Cell Death Dis 3: e427, 2012. PMID: 23171847. DOI: 10.1038/cddis.2012. 165

22 Lin PH, Lu YS, Lin CH, Chang DY, Huang CS, Cheng AL and Yeh $\mathrm{KH}$ : Vinorelbine plus 24-hour infusion of high-dose 5-fluorouracil and leucovorin as effective palliative chemotherapy for breast cancer patients with acute disseminated intravascular coagulation. Anticancer Res 30(7): 3087-3091, 2010. PMID: 20683060.

23 Esmon NL, Owen WG and Esmon CT: Isolation of a membranebound cofactor for thrombin-catalyzed activation of protein C. J Biol Chem 257(2): 859-864, 1982. PMID: 6895633.

24 Kobayashi N, Maekawa T, Takada M, Tanaka H and Gonmori $\mathrm{H}$ : Criteria for diagnosis of dic based on the analysis of clinical and laboratory findings in 345 DIC patients collected by the research committee on DIC in Japan. Bibl Haematol 49: 265275, 1983. PMID: 6667250.

25 Taylor FB Jr., Toh CH, Hoots WK, Wada H, Levi M, Scientific Subcommittee on Disseminated Intravascular Coagulation of the International Society on $\mathrm{T}$ and Haemostasis: Towards definition, clinical and laboratory criteria, and a scoring system for disseminated intravascular coagulation. Thromb Haemost 86(5): 1327-1330, 2001. PMID: 11816725. 
26 Gando S, Saitoh D, Ogura H, Fujishima S, Mayumi T, Araki T, Ikeda H, Kotani J, Kushimoto S, Miki Y, Shiraishi S, Suzuki K, Suzuki Y, Takeyama N, Takuma K, Tsuruta R, Yamaguchi Y, Yamashita N, Aikawa N and Japanese Association for Acute Medicine Sepsis Registry Study G: A multicenter, prospective validation study of the japanese association for acute medicine disseminated intravascular coagulation scoring system in patients with severe sepsis. Crit Care 17(3): R111, 2013. PMID: 23787004. DOI: $10.1186 / \mathrm{cc} 12783$

27 Ozaki T, Anas C, Maruyama S, Yamamoto T, Yasuda K, Morita Y, Ito $\mathrm{Y}$, Gotoh $\mathrm{M}$, Yuzawa $\mathrm{Y}$ and Matsuo S: Intrarenal administration of recombinant human soluble thrombomodulin ameliorates ischaemic acute renal failure. Nephrol Dial Transplant 23(1): 110119, 2008. PMID: 17804460. DOI: $10.1093 / \mathrm{ndt} / \mathrm{gfm} 563$

28 Nagato M, Okamoto K, Abe Y, Higure A and Yamaguchi K: Recombinant human soluble thrombomodulin decreases the plasma high-mobility group box-1 protein levels, whereas improving the acute liver injury and survival rates in experimental endotoxemia. Crit Care Med 37(7): 2181-2186, 2009. PMID: 19487933. DOI: 10.1097/CCM.0b013e3181a55184
29 Abeyama K, Stern DM, Ito Y, Kawahara K, Yoshimoto Y, Tanaka M, Uchimura T, Ida N, Yamazaki Y, Yamada S, Yamamoto Y, Yamamoto $\mathrm{H}$, Iino $\mathrm{S}$, Taniguchi $\mathrm{N}$ and Maruyama I: The n-terminal domain of thrombomodulin sequesters highmobility group-b1 protein, a novel antiinflammatory mechanism. J Clin Invest 115(5): 1267-1274, 2005. PMID: 15841214. DOI: $10.1172 / \mathrm{JCI} 22782$

30 Kadono K, Uchida Y, Hirao H, Miyauchi T, Watanabe T, Iida T, Ueda S, Kanazawa A, Mori A, Okajima H, Terajima $\mathrm{H}$ and Uemoto S: Thrombomodulin attenuates inflammatory damage due to liver ischemia and reperfusion injury in mice in toll-like receptor 4-dependent manner. Am J Transplant 17(1): 69-80, 2017. PMID: 27467205. DOI: 10.1111/ajt.13991

Received March 17, 2019

Revised April 16, 2019

Accepted April 19, 2019 